\title{
The Effects of Temporal Shut Down: A Proposed Mitigation on COVID-19 Perspectives
}

\author{
Bright Nana Kwame Ahia ${ }^{1,2 *}$, Elijah Asante Boakye ${ }^{1,2}$, Jacob Azaare ${ }^{1,2}$, Samuel Gyamerah ${ }^{1,2}$ \\ ${ }^{1}$ School of Management and Economics, University of Electronic Science and Technology of China, Chengdu, China \\ ${ }^{2}$ Center of West African Studies, University of Electronic Science and Technology of China, Chengdu, China \\ Email: ^obrempong0673@gmail.com, el.asante2@yahoo.com, azaarejacob@yahoo.com, Samuel.gyamerah@yahoo.com
}

How to cite this paper: Ahia, B. N. K., Boakye, E. A., Azaare, J., \& Gyamerah, S. (2020). The Effects of Temporal Shut Down: A Proposed Mitigation on COVID-19 Perspectives. Open Journal of Social Sciences, 8, 95-107.

https://doi.org/10.4236/jss.2020.812009

Received: October 18, 2020

Accepted: December 8, 2020

Published: December 11, 2020

Copyright (c) 2020 by author(s) and Scientific Research Publishing Inc. This work is licensed under the Creative Commons Attribution International License (CC BY 4.0).

http://creativecommons.org/licenses/by/4.0/

\section{Open Access}

\begin{abstract}
Notwithstanding various media reports on casualties in systems due to the emergence of COVID-19, it is envisaged to have a solution. By far, this study investigates how countries' bilateral trade relationship is distorted due to COVID-19. More so, it examines the economic and financial divergence in systems from the capital perspectives. Finally, it considers the changes in various industries that are affected directly as a result of the COVID-19 outbreak and its distortion in the business model. Employing a case study approach, we conclude that there is a distortion in the supply chain system which has effects on trade relationships. While significant capital deploying strategies were found as mitigation during the pandemics, there is an indecisive business model for the future with inordinate changes in business models during the periods of COVID-19. There is also a risk exposure in both economic decisions and business models due to the uncertain signals of COVID-19. We discuss our findings within the theoretical framework of capital allocation, information/signaling, and adoption perspectives.
\end{abstract}

\section{Keywords}

Bilateral Trade Relations, Business Model, COVID-19, Virus, Capital

Allocation

\section{Introduction}

Global prosperity depends on trade which dwells basically on supply chains. However, the supply chain has no further discussions without transportation. Such as transportation by foot, through to connectivity by air; thus, the transport industry is susceptible to economic growth, and its policies can either support or undermine growth. Dating back to 2002, the economic and financial system of 
China was distorted by the emergence of SARS. This led to the reports of many researchers considering the distortions that were introduced into different sectors of the economy. Some of these works include (Al-Hazmi, 2016) Al-Hazmi, who studied the challenges presented by Middle East respiratory syndrome (MERS) and severe acute respiratory syndrome (SARS) to global health and concluded that the Global health sector had learned many lessons through these outbreaks. He, however, pointed out that, the necessity for finding new antiviral action was not erudite. Factually, most of the studies within the period of the outbreak to date concentrated on the health risk, prevention, and control associated with the virus outbreaks.

Recently, some scholars (Al-Hazmi, 2016; Rahman Qureshi et al., 2020; Straub, 2009) reported their concerns about the emergence of SARS in mainland China. In their studies, they concluded on the fact that many geographical locations were affected and recording a death fatality ratio of $6.4 \%$. Although they pointed out that long term economic distortions were limited, its price is probably unaffordable. Again, they reported that the emergence of SARS was a scenario that led to the fundamental reform of the Chinese health system. Not denying that fact, the epidemics improved infrastructures, surveillance systems, and the ability to retort to health crises. In particular, the establishment of an internet-based disease reporting system nationwide has curbed enough of the consequences.

The Corona Virus Disease 2019 (COVID-19) is described as a transmissible disease which is caused by severe acute respiratory syndrome coronavirus 2 (SARS-CoV-2) (Zimmermann \& Curtis, 2020). This new strain of the virus which had not been formerly known to live in humans was detected in the city of Wuhan (Hubei Province) in China. With phlegm production, shortness of breath, and cough as its non-specific symptoms, the main medium of spread is through respiratory droplets. COVID-19 has an estimated incubation period of 2 - 14 days with no current vaccine to forestall its threats. Additionally, no conclusions have been reached in finding a cure as much its nature and dynamics are still unknown. The World Health Organization (WHO), in January 2020 declared a public health emergency globally (WHO, 2020). With the situation increasing rapidly, COVID-19 has led to an upsurge in the number of severe pneumonia cases outside China, including America, Europe, and Africa. The World Health Organization (WHO) reports a total of 47,894,604 cases with 88,174 in severe conditions. As of $4^{\text {th }}$ November 2020, COVID-19 had claimed $1,221,340$ lives and is affecting 214 countries and territories. With a fatality rate of $\sim 3.4 \%$ and a transmission rate of 2 - 3 newly infected from 1 case, the United States of America, India, Brazil, Russia, and France are the top five countries with total confirmed cases and as against a total worldwide recovery of 33,899,852 (COVID-19 Statistics, 2020).

Interestingly, despite all the effects posed by these viral outbreaks, very few concerns are directed to its consequences on the economic, financial, and business model decisions. Even if any exist, it's at its early stages and is forgotten af- 
ter eradication of the virus. Concerns related to long-run effects are not assessed.

The COVID-19 outbreak in China has brought numerous discussions on the global view. Daily News reports from almost all countries contain an iota of related COVID-19 issue. Although the world health organization has published COVID-19 as a global issue, research concern is limited in its bilateral trade relation intervention, how to overcome it, and how to prepare for the future. It is against this background, and the authors want to study the boomerang effects of this outbreak in distorting the bilateral trade relationships between China and the neighboring countries and the world at large while considering the future trend and after match of COVID-19.

In this work, we intend to make three distinct contributions to literature. First, we study how China's bilateral trade relationship "import and export" is distorted due to COVID-19. Secondly, we examined the economic and finance divergence in the Chinese economy (Capital perspective) as a solution. Thirdly, study the changes in various industries that are affected directly as a result of the COVID-19 outbreak (distortion in the business model). It also explores the awareness, expertise, and knowledge to address the potential applicability of theories enabled to reshaping economies, countries, and the world at large in this pandemic season.

The design is explorative as it employed the use of numerous articles, journals, and online surveillance to observe and understand the COVID-19 phenomenon in business perspectives and the related upshot of countries. While considering a case study method for countries in the pandemics, the authors specifically focused on the vital economic sectors of China since it is the first to have a hit on the COVID-19 cases. Their ways of handling the incidents leading to successful methods are mostly considered and communicated for countries at their earlier hits of the pandemic. However, statistics, information (as primary data), and secondary data on COVID-19 were apparently unavailable since it is in its early stage. Therefore, to present a building block, we analyze based on situational applicability and success factor consideration which were seen as yardsticks for mitigating COVID-19 and reshaping some sectors of most economies in the pandemic season.

The rest of this article follows; session one follows the introduction with import and export fluctuations during the outbreak and its' distortions in the bilateral trade relationships of countries, session two considers the theories and policy considerations in curbing the emergence of such events. At the same time, analysis and conclusion are presented at the end.

\subsection{Virus Outbreak and Its Interference on Bilateral Trade Relations}

Research in the scientific and pharmaceutical fields elaborates more on viruses, causes, spread, and control. See the following for more insight (Buckley, Kimberlin, \& Whitley, 2005; Caglioti et al., 2013; Chang, 2011; Gessain \& Cassar, 2012; Guzman et al., 2016; Lazear \& Diamond, 2016; Rehermann \& Nascimbeni, 
2005). All these papers, see the virus as a concern in the field of biological science. For that matter, its effect on finance and economics is limited. However, courting back to seminary papers, we found that the cost inflated in the economy and the damages introduced into the system tend to be higher than the actual field with which it is acclaimed.

China has had a reputable report in dealing with other countries, continents, and the world in general. According to Workmanh (2020) (China's Economy Grows 6.7 pct, Remains Global Growth Driver, n.d.), China experienced a 6.7\% expansion in economic growth as of 2017. This is due to trade. The trade partners of China are increasing with the introduction of more flexible trade openness policies. Presently, China trades with the United States, Hong Kong, Japan, Germany, Russia, Ghana, United Kingdom, etc. (China’s Top Trading Partners 2019).

Currently, uncertainty exposure as a result of COVID-19, which has brought the second world's largest economy to its knees remains questionable. Countries whose imports largely depend on China are in a state of dilemma whether to continue or seek new trade partners in other continents. Inflation in most of these countries is shooting up slowly since the emergence of COVID-19. This has been suspected to the temporary lockdown of industries including manufacturing, transportation, etc. Economically, more money chases fewer goods. However, the export of goods produced in China to other countries has reduced for the first quarter of the year 2020, causing about fifty billion dollars (\$50bn) reduction in the global shipmen (Drop in China Exports Causes \$50bn Fall in Global Shipments: UN|India News|Al Jazeera, 2020). Therefore, there is an expectation of high inflation in China and Chinas' economically dependent countries. Although early 2001 to 2016, there has been increasing export of medical equipment in quality and quantity, it is already announced that the export of medical equipment to other countries depending on China has reduced (Brown, 2020; Torsekar, 2018). This is envisaged as a treat exposure to the world health organization (WHO), whose job is to assist countries in need. However, the question is, is WHO capable of supporting all expected infected countries in the long run of the COVID-19 pandemic?

\subsection{Industrial Sectors and Their Reactions during COVID-19 Outbreak}

In most cases, it is rational to think of the uncertainties that accrue as a result of epidemics. This raises numerous questions in mind. Consider the following questions in the twenty-first century. What will be the business models after the coronavirus? When are businesses resuming job? Is COVID-19 a hazard at the job center? Will COVID-19 come to live within the workplace? What's going to be the state of economies in the long-run effect? All these questions posit the unforeseen expectations and preparations that need to be made in combating post COVID-19.

Generally, there is a transition in business models from time to time. Appar- 
ently, businesses that operate on the "Brick and Mortar" basics are trying to consider a "Click and Mortar" concept. Similarly, a company that operates on "Click and Mortar" is trying to work solely on Click concepts. It is realized that during the COVID-19 period, most countries who have been affected tried converting services that are offered on "face to face" to click essential thus online perspectives. A typical example is the shutdown of physical communications in schools but converting them into online classes. Economically, shareholders, managers, and customers would analyze the cost, risk, and benefits of this model in decision making. Though it may be argued for services that do not include much physical contact, most organizations that are into the productions of goods are equally considering ventilation and spacious working places which is mitigation to the spread of COVID-19 in the production centers. Therefore, the question as to when businesses will resume work is pending since jobs are carried out within a spacious environment or online.

Although transportation has been an importation industry that has elevated many countries' economies, including China, it's interesting to note that China's effort in this industry has been persistent recently. In subsidy, research and Development $(R \& D)$, and innovation, China is rated among the first five in the world (Is China Leading in Global Innovation?|China Power Project, 2019). China's subsidy in the transportation industry has increased over the years and is expected to continue until it becomes the world's most populous leader in the transport industry. However, guess the discrepancies that arose as a result of COVID-19 in the transport industry. It is envisaged that the contribution of the transport sector will reduce by 2021 analysis due to transport restrictions.

The airline industry in China has rapidly improved and plays an increasingly important role in the national economic development agenda. The China Civil Aviation industry has shown momentum development. It's now regarded as the fastest-growing aviation market in terms of annual additional Origin-Destination passengers (constant policies scenario) of 1 billion new passengers for a total of 1.6 billion against the US of 481 million new passengers for a total of 1.3 billion from 2017 (IATA, 2018). But, COVID-19 prevention and control measures led to the grounding of airplanes from China to other countries and vice versa; therefore, distorting the supply chain system and other economic activities that accrue to movement. This is a treat to the bilateral relationship between China and other related countries. Such countries may seek to sign a new relationship with other emerging or developed economies in search of dependence and sustainability in the $21^{\text {st }}$ century, still the destruction of COVID- 19 .

We, therefore, based on the above arguments to state that COVID-19's emergence will distort the bilateral relationships of affected countries and hence, increase the cost of living due to high inflation. COVID-19 has led to policy consideration between China and other countries (Trade Trilateral Targets China's Industrial Subsidies|Center for Strategic and International Studies, 2020).

Apparently, there is no expert suggestion or conclusions on when COVID-19 will end. Businesses are not willing to shut down for long periods since it may 
arise to global crises, thus famine, which may not be easily supported due to the mode of spread of the virus. Enforcing employees to work may also lead to entrusting their lives into the hands of their employers. Probably this may change the contractual agreement between them. It is up to various countries or on the global decision to conclude who bears the risk of diagnosed COVID-19 patients in the workplace.

While some countries are in the dormant period, others are now hitting the peak. In as much as movements haven't been limited, there is a difficulty to tell when the virus will be said to have come to an end. Although our focus, China, for some period didn't record cases in some provinces after a while, there is no evidence of concluded eradication of COVID-19. This was speculated to be the cases of persons who have either not fully recovered, had a dormant temporal virus, system failure, etc. The perceptions about COVID-19 which haven't been certified make it difficult to conclude if the virus by far will be considered a permanent one or a completely eradicated virus. Currently, the virus identified as a global pandemic has been tackled by the world health organization (WHO) globally enforcing some measures (social distancing, constantly washing hands under running water with soap, preventing handshakes and not touching the face with hands, wearing facial masks if in public and above all staying at home if not for very important and necessary reasons) that must be implemented in various countries. These measures may be challenging to adhere to if not for financial reasons, meeting economic demands, and others. Therefore, e-commerce concepts will be considered during and after the scene of COVID-19 in most business centers since the preventive measures exhibit their features.

In Figure 1, we discussed the industrial perspective demand for human and technological capital before and during COVID-19 pandemics. Proposing from E-commerce, almost all businesses operate under the following:

1) Click: Where businesses operate totally on a virtual space. Performing online services such as after-sales service that are delivered to third parties who does not need face to face communications. For example, medical doctors creating stores online to purely service customers and recommend drugs.

2) Click and Mortar: Where businesses operate with an online system and physical existence of shops. Here customers are serviced both on face-to-face interaction and online services. Example banks

3) Brick and Mortar: Where businesses exist solely on physical existence and need only a face-to-face interaction before transactions can take place. An example is the local farmers who have no idea of technological advancement due to the digital divide.

We, therefore, classify all business under either of the following and convey our findings for the implementation in the COVID-19 periods and afterward expectations.

\subsection{Conceptual Perspective (prior, during and after COVID-19)}

The future, after COVID-19, is not determined. Uncertainty in business models, 


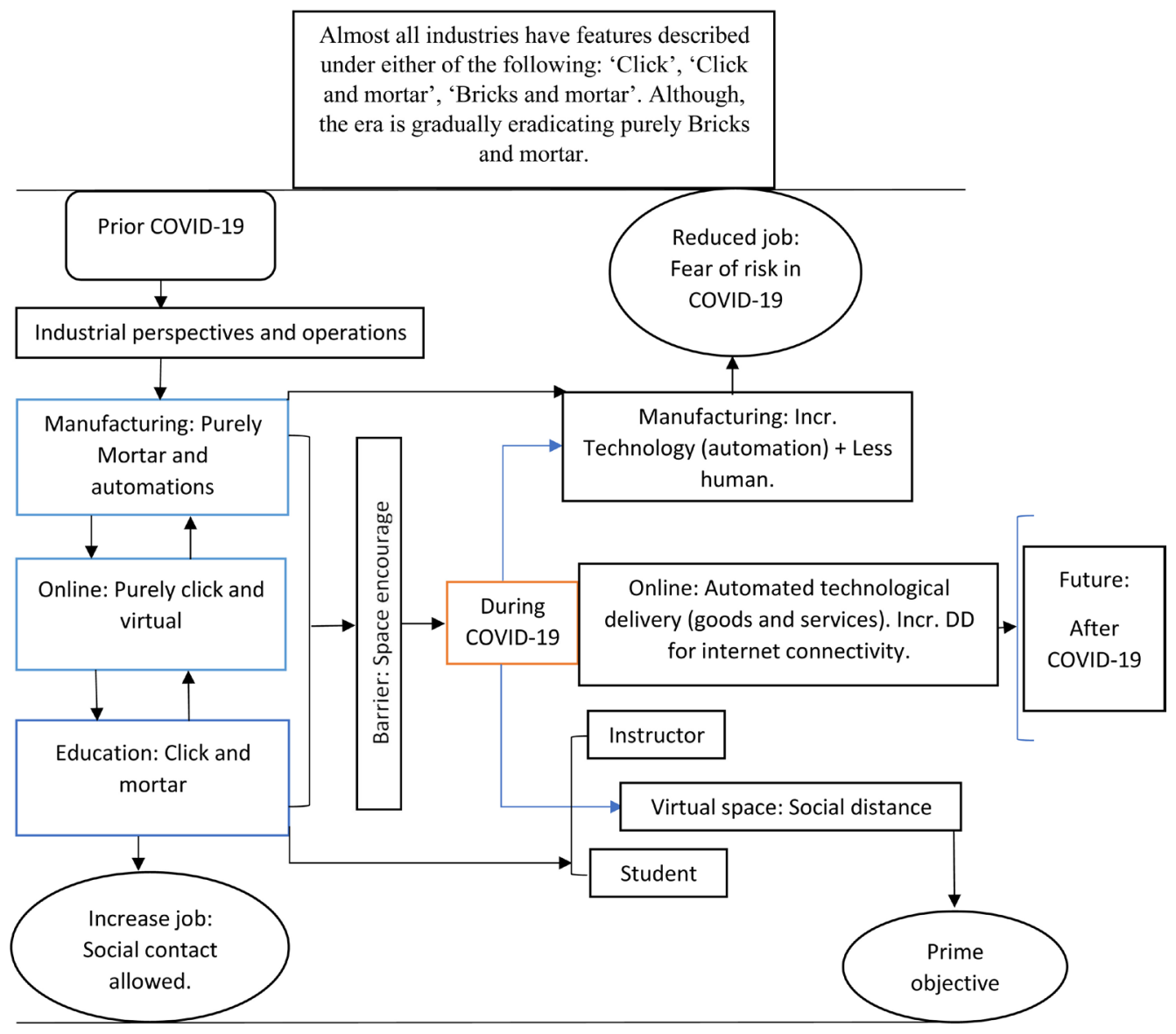

Figure 1. Industrial perspectives: demand for human and technological capital. Source: by Authors.

economic and financial decisions. A treat to economic performance, countries' decisions, and the world at large. From the framework, we present three different stages. Stage one encompasses the prior COVID-19. In this stage, industrial perspectives and operations were running solely on morta and automation, click and virtual, and click and morta. Also, at this stage, there was increasing contact of persons, and job creation was within the average standard. The second stage is where COVID-19 existed. At this stage, initially, there was an increase in automation and reduced human performance. Also, there was an increase in the demand for internet connection since one best way to mitigate the virus was less contact. This increased social distancing. The final stage is the future after COVID-19. This stage is uncertain and is the basic building block for this research. Thus, the uncertainties that arise as the shot-downs are observed on the economy at large.

\section{Theoretical Perspective}

The newness of the virus outbreak has been a bottleneck for experts and researchers in determining which or what theories are best applicable in the scene. However, we based on the various paths of countries that were earlier destructed by the pandemic in proposing the following theories. Considering the early De- 
cember, the virus's origin was unknown till late January and early February. At this point, the scenario was just like a comedy although the breeze of it was blowing hard through China, Italy the United States and the likes. Its description of outlying crown-like pins led to the origination of the name coronavirus (Shereen et al., 2020). Their miniature disposition contains a nucleic material with one-stranded RNA having between 26 - $32 \mathrm{kbs}$ in length. The subgroupings of coronaviruses comprise the H5N1 influenza A, H1N1 2009, Middle East respiratory syndrome coronavirus (MERS-CoV), and severe acute respiratory syndrome coronavirus (SARS-CoV). Coronaviruses, just before the world experienced a severe acute respiratory syndrome (SARS) outbreak in 2002, were only known to infect animals (Zhong et al., 2003). The brutality of coronaviruses can progress into acute respiratory distress syndromes, sepsis, septic shock, and serious pneumonia which may cause death (Alexandria et al., 2016).

\subsection{Capital Allocation Theory}

In dealing with monetary theory, individual perceptions are always kept in mind. Thus, on average the individual is concerned with the consumption of goods. Capital theory, in its basic foundation, seeks to develop the optimal allocation of resources over time. Basically, earlier fatalities of the pandemic probably caused China to adopted the concept of deploying capital resources to optimally allocate the situation under rational conditions while ensuring a lockdown strategy. According to Hjelmgaard et al. (2020), they implemented subsidy theories that were related to research and development $(R \& D)$ on cure and prevention, subsidy on goods and basic amenities, subsidy on transportation for essential and necessary movements, subsidy on medications related to COVID-19, subsidy on hospital facilities, etc. (Hjelmgaard, Lyman, \& Shesgreen, 2020). They also considered halting specific policies that were subsidy related. Although they do not have an immediate concern on the pandemic such as subsidy on the production of goods and services that is not a necessity; building electronic vehicles, production industries were equally on lockdown while they observe the cases over periods. These were capital related activities which were economic factors that will contribute to gross domestic product (GDP) within the shortest possible period. However, the expert's analysis forecasted the benefits of the immediate lockdown to be over and above the future benefits that will be accrued to the country in the long-run if lockdowns are not implemented. Thus lockdown restrictions have an unfortunate implication on capital allocation at the initial stage, and its benefits outweigh the long-run costs and vice versa. Similarly, Italy observed the same restriction conditions and it turned out as a good result. In a nutshell, these processes were meant to ensure the following: reducing the rate of spread, curing the already existing cases, and apparently, eradicating the situation.

\subsection{Signaling Theory/Information Asymmetric}

In a perfect system, at any given time, decision-makers are said to be rational 
and that decisions incorporate all the available information about that system. Thus, experts, at the country level, firm-level, and even individual homes are said to have the same information about the prospects, opportunities, and challenges. Their decisions are reflected in all their activities. However, the systems are not perfect due to information asymmetry between countries in the case of COVID-19. Presidents, ministers, and other heads of states tend to have better information about the countries and are also perceived to make individual decisions or apply specific policies estimated to intended or conceal the country's actual economic benefits.

We argue heads of states have better information about the countries performances on the international market and therefore, send signals of favorable conditions to the people of that country. To encourage these acts, heads of states have some incentives to help them voluntarily disclose additional information as a signal to promote others in handling cases of this within the pandemic period. This will help to attract and strengthen the bilateral relationship between countries since relationships could be defined beyond trade agreements. Some countries can manipulate and send attractive information due to information asymmetric, and this may necessarily not only help the other party but also to strengthen relationships.

\subsection{Adoption Theory}

This theory examines the choices an individual makes to accept or reject a particular innovation. Apparently, adoption is not only the choice to take an innovative act but also how to incorporate/integrate a particular innovation into an existing system in the appropriate context. Adoption theories have come out of numerous fields including medical health, education, sociology, etc. with economics and finance inclusive (Hall \& Loucks, 1978; Deffuant et al., 2005; Rogers, 1995). We suppose the current pandemic and its intricacies can be mitigated using adoption theories. Thus, the various curbing processes available in neighboring countries can be a learning procedure for countries that are still in the situation. These models can be adopted based on the following strategies Rogers innovation diffusion theory, concern based adoption model, technology acceptance model, and the united theory of acceptance and technology as discussed in the research of (Rogers, 1995). We propose that the individual country level considers the concern-based adoption model while keeping the technology acceptance model in mind. However, from a global perspective, the unified theory of acceptance and technology models should be considered.

\section{Analysis and Discussion}

This article intends to first, study how China's bilateral relationship is distorted due to COVID-19. Secondly, we examined the economic and financial divergence in the Chinese system from capital perspectives and finally considered the changes in various industries that are affected directly as a result of the 
COVID-19 outbreak and its distortion in the business model.

In the quest, we found that COVID-19 emerged in late 2019 but early 2020 . Due to its unfamiliar nature, first hitters struggled with preventive and control measures leading to more significant expenses on capital. While most of its features were realized in the latter days of the second month in 2020, most businesses and production centers were contaminated; therefore, a lot of fatal cases were recorded. Lately, did the world realized COVID-19's mode and rate of spread was through social gathering; hence, a band on movement in most countries, making it a worldwide crisis (pandemic). This is again expected to lead to an economic crisis (inflation). We also found that there is a distortion in the supply chain system, which extends to trade relationships since dependent countries could not get delivery from production countries leading to trade distractions. This is due to specific laws that were seen as mitigations to COVID-19 by reducing spread and infections. Band imposed on most production companies presented experts to envisage high inflation forecast and reduction in the economic performances of some countries, therefore, affecting GDP and decreasing the standard of living.

We also found that the Chinese government deployed enough capital resources to quicken the process of curbing the hit of COVID-19. Though this process brought about changes in subsidy policies, it is forecasted to have more enormous benefits in the future of China if compared to the losses today. However, the large capital deployed in the process produced positive results serving as a benchmark for today's hitters of COVID-19.

Finally, we found that COVID-19 did not just affect a particular industry, but significantly almost all aspects of businesses were affected. The emergence brought about changes in business models, practices, and implementations. Although COVID-19 brought about difficulties, it also created a sense of self-awareness of the centuries in which we are. Thus, technological driven century, where technology is a great factor to be considered in most centers than human capital. Will the world in few years to come need no social (human) services? Before, during, and after the COVID-19 pandemic business practices projects the answer.

\section{Conclusion and Recommendation}

It is concluded that COVID-19 is a world crisis that brought the second world's largest economy to its knee while distracting the decision of the world's first economy. However, while capital allocation theories are highly recommended, most of the COVID-19 victimized countries that are underdeveloped are finding it difficult to subsidize through capital deploying while ensuring total eradication of the cases recorded as practiced in China. Also, due to the distortion in economic performances, certain countries such as Germany, Ghana, the USA, and the likes are reluctant in considering total lockdown which though is aimed at ensuring a stable economy its price may be higher as proposed by experts. 
COVID-19 has brought about destruction in the bilateral relationships between countries and reduced the flow of the supply chain processes. Also, to ensure total eviction of COVID-19, capital structure amendments need to be implanted with lockdown procedures while considering the future of economic performances today.

Furthermore, business models and practices as of today have changed compared to prior COVID-19. This is not limited to a particular sector but all aspects of businesses. For example, the future of the educational industry is indecisive since all "bricks and mortar" before COVID-19 are currently conducted virtually and seems to support all teaching and learning practices. However, it has strengths, weaknesses, opportunities, and threats (SWOT) which need expert analysis.

Overall, we consider the COVID-19 pandemics, emergence, features, and proposed mitigations to convey certain practices that will produce successful results to countries in their early, middle, and late stages of the pandemic. This is highly recommended for Africa, Asia, America, Europe, and Australia countries

\section{Acknowledgements}

The authors gratefully acknowledge the financial support of the Ministry of Education of Humanities and Social Science Grant of China (Grant Number: 17YJC790127) and the University of Electronic Science and Technology of China.

\section{Author Contributions}

This article was written as an emerging issue. The following authors contributed to the success of this work. Bright Nana Kwame Ahia: Conceptualization, Methodology, Formal Analysis, Writing-Original Draft. Elijah Asante Boakye, Jacob Azaare, and Samuel Gyamerah: Writing-Review and Editing.

\section{Conflicts of Interest}

The authors declare no conflicts of interest regarding the publication of this paper.

\section{References}

Alexandria et al. (2016). An Assessment of the Clinical Learning Environment from Respiratory Care Students during Internship Rotations: A Pilot Study. Respiratory Care, 61, OF49-OF49.

http://search.ebscohost.com/login.aspx?direct=true\&db=ccm\&AN=116832977\&site $=e$ host-live\&scope $=$ site

Al-Hazmi, A. (2016). Challenges Presented by MERS Corona Virus, and SARS Corona Virus to Global Health. Saudi Journal of Biological Sciences, 23, 507-511. https://doi.org/10.1016/j.sjbs.2016.02.019

Brown, C. P. (2020). COVID-19: China's Exports of Medical Supplies Provide a Ray of Hope. Massachusetts: Peterson Institute for International Economics. 
https://www.piie.com/blogs/trade-and-investment-policy-watch/COVID-19-chinas-ex ports-medical-supplies-provide-ray-hope

Buckley, K. S., Kimberlin, D. W., \& Whitley, R. J. (2005). Neonatal Herpes Simplex Virus Infection. In Herpes Simplex Viruses (p. 1). Media Network.

Caglioti, C. et al. (2013). Chikungunya Virus Infection: An Overview. New Microbiologica, 36, 211-227.

Chang, M. H. (2011). Hepatitis b Virus Infection. In Liver Disease in Children (4th ed.).

China's Economy Grows 6.7 pct, Remains Global Growth Driver. http://www.ecns.cn/business/2017/01-20/242618.shtml

China's Top Trading Partners 2019. http://www.worldstopexports.com/chinas-top-import-partners

COVID-19 Statistics (2020). COVID-19 Coronavirus 2019-NCov Statistics Update (Live): 3,121,118 Cases and 216,508 Deaths.

Deffuant, G., Huet, S., \& Amblard, F. (2005). An Individual-Based Model of Innovation Diffusion Mixing Social Value and Individual Benefit. American Journal of Sociology, 110, 1041-1069. https://doi.org/10.1086/430220

Drop in China Exports Causes \$50bn Fall in Global Shipments: UN|India News|Al Jazeera. https://www.aljazeera.com/ajimpact/drop-chinese-exports-50bn-fall-global-export-200 304202316844.html

Gessain, A., \& Cassar, O. (2012). Epidemiological Aspects and World Distribution of HTLV-1 Infection. Frontiers in Microbiology, 3, 388. https://doi.org/10.3389/fmicb.2012.00388

Guzman, M. G. et al. (2016). Dengue Infection. Nature Reviews Disease Primers, 2, Article No. 16055. https://doi.org/10.1038/nrdp.2016.55

Hall, G., \& Loucks, S. (1978). Teacher Concerns as a Basis for Facilitating and Personalizing Staff Development. Teachers College Record, 80, 36-53.

Hjelmgaard, K., Lyman, E. J., \& Shesgreen, D. (2020). Coronavirus: This Is How China Beat COVID-19. Could America Handle It? USA Today. https://www.usatoday.com/story/news/world/2020/04/01/coronavirus-COVID-19-chin a-radical-measures-lockdowns-mass-quarantines/2938374001

IATA (2018). IATA-IATA Forecast Predicts 8.2 Billion Air Travelers in 2037.

Is China Leading in Global Innovation?|China Power Project. https://chinapower.csis.org/china-innovation-global-leader

Lazear, H. M., \& Diamond, M. S. (2016). Zika Virus: New Clinical Syndromes and Its Emergence in the Western Hemisphere. Journal of Virology, 90, 4864-4875.

https://doi.org/10.1128/JVI.00252-16

Rahman Qureshi, U. U. et al. (2020). Outbreak of Novel Corona Virus (2019-NCoV): Implications for Travelers to Pakistan. Travel Medicine and Infectious Disease, 34, Article ID: 101571. https://doi.org/10.1016/j.tmaid.2020.101571

Rehermann, B., \& Nascimbeni, M. (2005). Immunology of Hepatitis B Virus and Hepatitis C Virus Infection. Nature Reviews Immunology, 5, 215-229. https://doi.org/10.1038/nri1573

Rogers, E. M. (1995). Elements of Diffusion. In Diffusion of Innovations (4th ed.). New York: The Free Press.

Shereen, M. A. et al. (2020). COVID-19 Infection: Origin, Transmission, and Characteristics of Human Coronaviruses. Journal of Advanced Research, 24, 91-98. 
https://doi.org/10.1016/j.jare.2020.03.005

Straub, E. T. (2009). Understanding Technology Adoption: Theory and Future Directions for Informal Learning. Review of Educational Research, 79, 625-649. https://doi.org/10.3102/0034654308325896

Torsekar, M. P. (2018). China's Changing Medical Device Exports. Journal of International Commerce and Economics, 1-15.

https://www.usitc.gov/journals.

Trade Trilateral Targets China's Industrial Subsidies|Center for Strategic and International Studies.

https://www.csis.org/analysis/trade-trilateral-targets-chinas-industrial-subsidies

WHO (2020). Coronavirus (COVID-19) Events as They Happen.

https://www.who.int/emergencies/diseases/novel-coronavirus-2019/events-as-they-hap pen

Zhong, N. S. et al. (2003). Epidemiology and Cause of Severe Acute Respiratory Syndrome (SARS) in Guangdong, People's Republic of China, in February, 2003. The Lancet, 362, 1353-1358. https://doi.org/10.1016/S0140-6736(03)14630-2

Zimmermann, P., \& Curtis, N. (2020). Coronavirus Infections in Children Including COVID-19: An Overview of the Epidemiology, Clinical Features, Diagnosis, Treatment and Prevention Options in Children. The Pediatric Infectious Disease Journal, 39, 355-368. https://doi.org/10.1097/INF.0000000000002660 